\title{
EXPERIMENTAL MEASUREMENT OF THE AERODYNAMIC CHARATERISTICS OF TWO-DIMENSIONAL AIRFOILS FOR AN UNMANNED AERIAL VEHICLE
}

\author{
Luis VELAZQUEZ; Jiří NOŽIČKA, Jan VAVŘín
}

\begin{abstract}
This paper is part of the development of an airfoil for an unmanned aerial vehicle (UAV) with internal propulsion system; the investigation involves the analysis of the aerodynamic performance for the gliding condition of two-dimensional airfoil models which have been tested. This development is based on the modification of a selected airfoil from the NACA four digits family. The modification of this base airfoil was made in order to create a blowing outlet with the shape of a step on the suction surface since the UAV will have an internal propulsion system. This analysis involved obtaining the lift, drag and pitching moment coefficients experimentally for the situation where there is not flow through the blowing outlet, called the no blowing condition by means of wind tunnel tests. The methodology to obtain the forces experimentally was through an aerodynamic wire balance. Obtained results were compared with numerical results by means of computational fluid dynamics (CFD) from references and found in very good agreement. Finally, a selection of the airfoil with the best aerodynamic performance is done and proposed for further analysis including the blowing condition.
\end{abstract}

\section{INTRODUCTION}

According to the evolution of unmanned aerial vehicles, commonly referred to as UAVs, several investments have been increasing every year, especially in the field of aerodynamic characteristics which can be obtained through wind tunnel tests. In the Laboratory of Fluid Mechanics at the Czech Technical University in Prague, particularly in the branch of aerodynamics, an UAV with an internal propulsion system is being developed and therefore all its components must be designed. This paper is a part of the development of the airfoil and includes the results of wind tunnel tests of a twodimensional NACA 2415, taken as the base airfoil, measuring lift, drag forces and pitching moment. The modification of this base airfoil was made in order to create a blowing outlet with the shape of a step on the suction surface located at $30,40,50$ and 60 percent of the cord. Therefore, four modified models of this airfoil were made and tested by an aerodynamic measuring system composed by a closed circuit wind tunnel and an aerodynamic wire balance. Lift, drag and pitching moment coefficients versus the angle of attack were obtained for all the models tested and were compared to numerical results obtained in [5] for the situation where the engine of the aerial vehicle is turned off, called the no blowing condition and found in good agreement. Based on these results a selection of the airfoil with the best aerodynamic performance is done and proposed for further studies. The whole process is described in the following sections.

¿Luis Velazquez, Jiří Nožička, Jan Vavřín; luis.velazquez@fs.cvut.cz. Faculty of Mechanical Engineering, Czech Technical University in Prague, Techicka 4, 16606 Praha 6. 


\section{Measurement System Apparatus}

The measurement system includes three components, a low speed wind tunnel system, the aerodynamic balance and data processing software.

\subsection{Wind TUNNEL SYSTEM}

The closed-circuit wind tunnel has an open test section of $750 \times 550 \mathrm{~mm}$ cross section. It is assembled from straight parts of a closed-return passage with rectangular cross section, elbows with corner-vanes, a rectangular settling chamber and a nozzle. The honeycomb and two screens are placed in a closed-return passage. The maximum air velocity of $17 \mathrm{~m} / \mathrm{s}$ can be obtained in the test section. A $55 \mathrm{~kW}$ three-phase induction motor and a frequency changer are coupled with fan. The wind tunnel has a turbulence intensity at a velocity of $7,5 \mathrm{~m} / \mathrm{s}$ of $1,3 \%$ [9]. The flow velocity was measured directly with an anemometer vane type.

\subsection{AERODYNAMic BALANCE}

The structure of the balance can be seen in Fig. 1. The balance is composed of six high precision digital hanging scales with a capacity of $50 \mathrm{~N}$ and a resolution of $0,02 \mathrm{~N}$ located according to Fig. 2 .

Six forces are measured in scales A, B, C, D, E and $\mathrm{F}$. The wires attached to $\mathrm{A}$ and $\mathrm{B}$ are parallel to the incoming velocity vector and define a plane which is taken as a reference plane for the balance ( $x-y$ plane), these wires point in the $x$ direction.

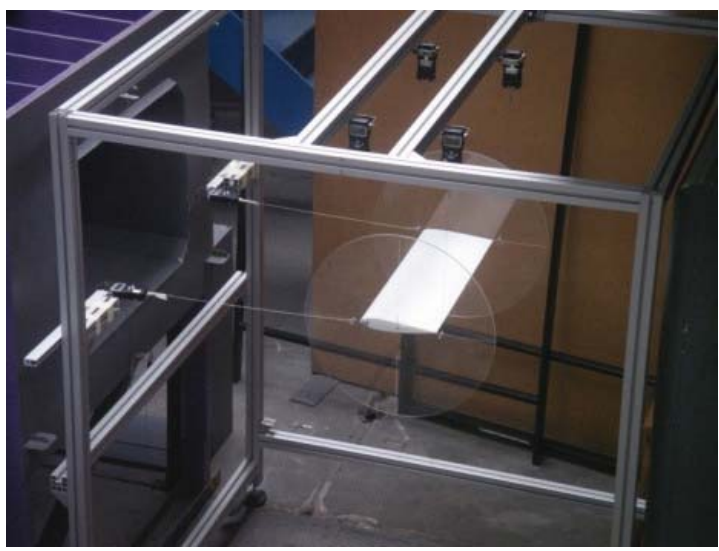

Fig. 2. Location of scales in the

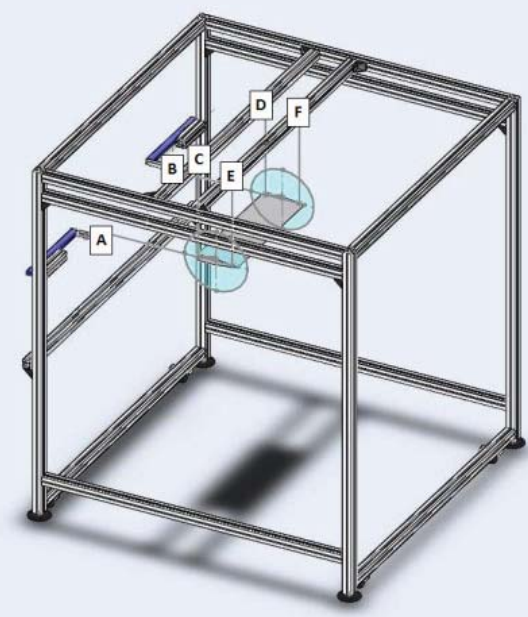

Fig. 1. Structure of the aerodynamic balance.

The wires attached to $C$ and $D$ are in a plane that is perpendicular to the $x-y$ plane, which is designate the $y-z$ plane. Wires containing $A$ and $C$ are attached to a common point on the left side of the wing. Wires containing $B$ and $D$ are attached to a common point on the right side of the wing. Finally wires attached to $\mathrm{E}$ and $\mathrm{F}$ are parallel to those ones attached to $C$ and $D$. aerodynamic balance.

The airfoil is attached to two endplates of transparent polycarbonate, these endplates have the main function of reducing considerably the strength of the tip vortices and the induced drag by blocking the leakage around the wing tips [2]. The balance can

¿Luis Velazquez, Jiří Nožička, Jan Vavřín; luis.velazquez@fs.cvut.cz. Faculty of Mechanical Engineering, Czech Technical University in Prague, Techicka 4, 16606 Praha 6. 
produce angle of attack ( $A O A$ ) changes from 0 to 16 degrees manually with the smallest increment of 2 degrees.

\subsection{Data AcQuisition and Processing}

The procedure for the acquisition and processing the data is in agreement to the procedure for wire balances followed in [3], attaching the model in an inverted position (upside down) so that aerodynamic lift added to the weight to prevent unloading the wires as the resulting tension can never be allowed to diminish to zero.

Since the horizontal wires $A$ and $B$ cannot transmit bending, the vertical force perpendicular to the flow velocity vector, the lift, is obtained from the sum of the forces in the vertical wires:

$$
\mathrm{F}_{\mathrm{L}}=\mathrm{C}+\mathrm{D}+\mathrm{E}+\mathrm{F}
$$

The drag is the sum of the forces in the two horizontal wires parallel to the direction of the flow velocity:

$$
\mathrm{F}_{\mathrm{D}}=\mathrm{A}+\mathrm{B}
$$

The pitching moment is about the $y$ axis is given by:

$$
M_{P}=(E+F) \times b
$$

where $b$ is the distance between the lines containing $C, D$ and $E, F$.

All obtained data is collected manually and then processed using calculation software. Then, the general equations to calculate lift, drag and pitching moment coefficients were used as follow:

$$
\begin{gathered}
C_{D}=\frac{F_{D}}{\frac{1}{2} \rho V^{2} A} \\
C_{L}=\frac{F_{L}}{\frac{1}{2} \rho V^{2} A} \\
C_{M}=\frac{M_{P}}{\frac{1}{2} \rho V^{2} A C}
\end{gathered}
$$

\subsection{Calibration of the Measurement System}

Since the lift is the largest force by far in a typical aircraft complete model wind tunnel work, extreme care must be taken to ensure that it is orthogonal to the other components [7]. Therefore, the most precise perpendicularity between the wires had to be maintained; otherwise some component of the drag could appear improperly in the lift and vice versa. Concerning the scales, a calibration testing process with low weights from $0,30 \mathrm{~N}$ to $1,00 \mathrm{~N}$ was held to observe if each scale was, in fact, measuring what it indicated. The resultant deviation of the scales was $\pm 0,02 \mathrm{~N}$. This possible measurement error for the used conditions represents approximately a change of 0,005 in the computed coefficients.

\section{Wind Tunnel Tests}

¿Luis Velazquez, Jiří Nožička, Jan Vavřín; luis.velazquez@fs.cvut.cz. Faculty of Mechanical Engineering, Czech Technical University in Prague, Techicka 4, 16606 Praha 6. 
Low Reynolds number wind tunnel tests on a two dimensional NACA airfoil and four modified models of this one were performed; these results were compared to reference numerical data.

A NACA 2415 airfoil, which has become increasingly popular on $1 / 4$ scale pylon racers [1], was tested as seen in Fig. 3. The coordinates were obtained from [4].

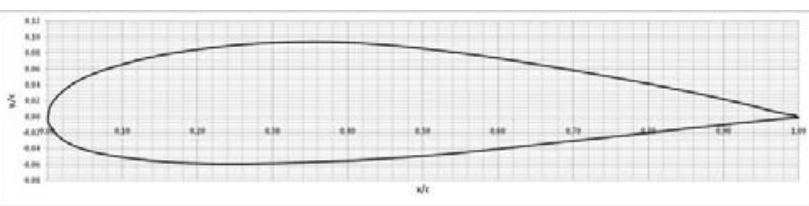

Fig. 3. NACA 2415 airfoil

The modification is based mainly on the creation of an abrupt step on the suction side of the original NACA 2415 airfoil. This step simulates a blowing propulsive outlet of the wing in normal flight conditions. The height of the step must be long enough in such a way that does not risk the stability of the structure of the wing model, for that reason the height of the step was defined as one third of the maximum thickness of the original airfoil which means 5 per cent of the chord. It is important to mention that the height of the step was kept constant to focus mainly on the influence of the location of the step along the chord line.

Four different configurations where designed which involved the location of the step at different strategical points chordwise. These points are:

- At the location of the maximum thickness: $30 \%$ of the chord (2415-3).

- At the location of the maximum camber: $40 \%$ of the chord (2415-4).

- Before the transition point (at 0 AOA): $50 \%$ of the chord (2415-5).

- Passed the transition point (at 0 AOA): $60 \%$ of the chord (2415-6).

Therefore, four models were built and also the original NACA 2415. Following the NACA numbering system, it was proceeded to assign an additional digit which indicates the position of the step chordwise in tenths of the chord.

The following equations were developed to obtain the ordinates passed the step, since the abscises and ordinates of the original airfoil are given with respect to the origin $(0,0)$, for $x=x_{s}$ :

for $x>x_{s}$ :

$$
y_{U m_{x=x_{S}}}=\left[y_{U}\right]_{x=x_{S}}-h_{S}
$$

$$
y_{U m_{x>x_{S}}}=\left[\frac{y_{U}-h_{S}}{y_{U}}\right]_{x=x_{S}} \cdot\left[y_{U}\right]_{x>x_{S}}
$$

where:

- $y_{u m}$ is the modified ordinate of the upper surface.

- $y_{U}$ is the upper-surface ordinate.

- $x_{s}$ is the abscise of the step.

- $h_{s}$ is the height of the step.

In Fig. 4 it is possible to see all the parameters involved in the modification of the base airfoil, in this case where the step is located at the maximum thickness point.

¿Luis Velazquez, Jiří Nožička, Jan Vavřín; luis.velazquez@fs.cvut.cz. Faculty of Mechanical Engineering, Czech Technical University in Prague, Techicka 4, 16606 Praha 6. 


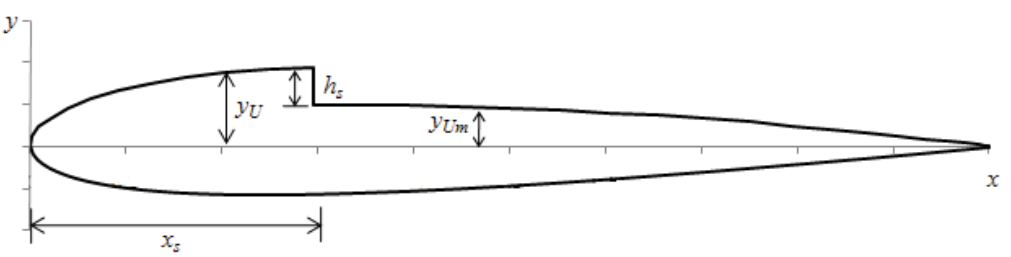

Fig. 4. Parameters involved in the modification of the base airfoil.

The resulting airfoils after the corresponding modifications are illustrated in Fig. 5 $a, b, c, d$.

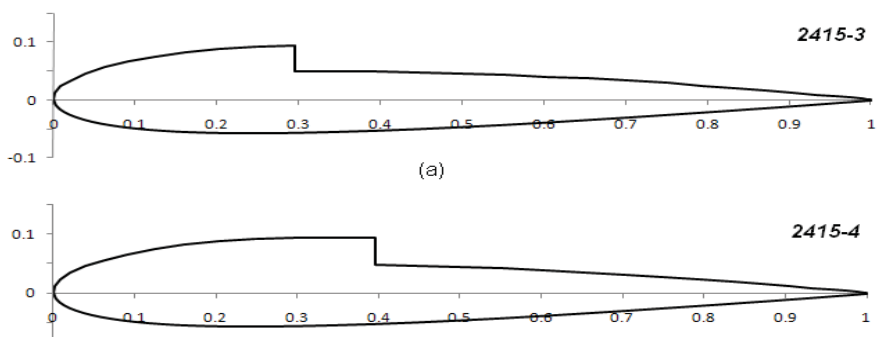

(b)

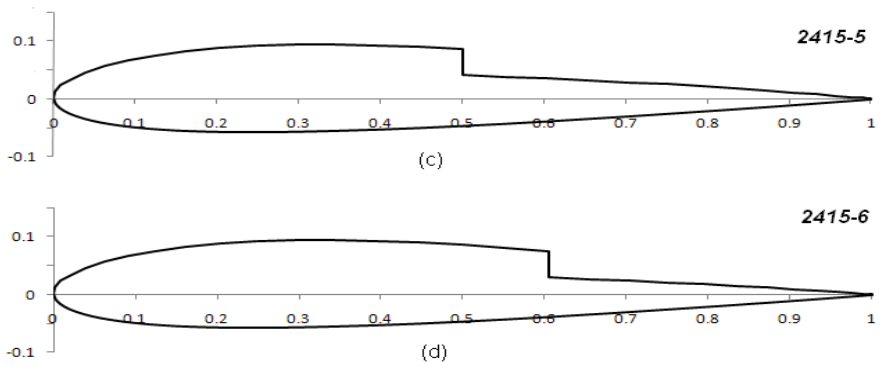

Fig. 5. Airfoils developed for testing (a) 2415-3, (b) 2415-4, (c) 2415-5, (c) 2415-6.

The NACA 2415 and all developed airfoil models built for testing (Fig. 5 a,b,c,d) have a chord length of $200 \mathrm{~mm}$ and a span of $600 \mathrm{~mm}$, which means an aspect ratio of 3 . The body of the models was made of expanded polystyrene foam (EPS) and coated with a layer of solid polystyrene as shown in Fig. 6 a,b.

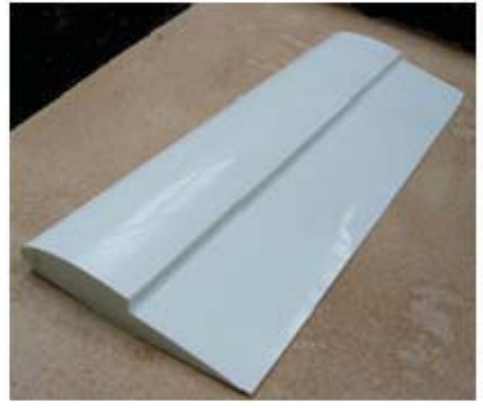

(a) 2415-5

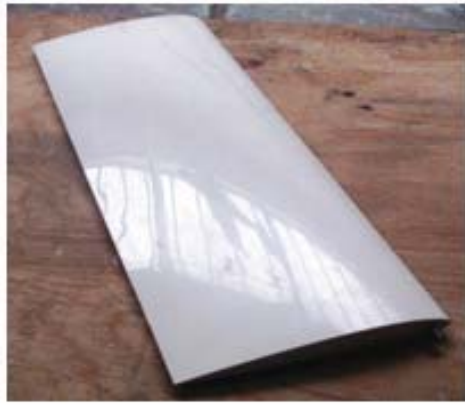

(b) NACA 2415

Fig. 6 a,b. Airfoil models for testing.

¿Luis Velazquez, Jiří Nožička, Jan Vavřín; luis.velazquez@fs.cvut.cz. Faculty of Mechanical Engineering, Czech Technical University in Prague, Techicka 4, 16606 Praha 6. 
In order to run the tests, the aerodynamic balance was fixed and aligned in the wind tunnel open test section, then the model previously attached to both endplates by means of screws and nuts was hanged in the four scales for lift which were attached to the balance structure and finally it was connected to the two drag scales forming an angle of 90 degrees. The wind tunnel tests were performed at a Reynolds number of 100000 which means a velocity of $7,7 \mathrm{~m} / \mathrm{s}$ according to the climatic conditions of the measurement days. The angle of attack was set from 0 to 16 degrees with an increment of 2 degrees [6]. The experimental results are validated with numerical results which will be also described later in the following sections.

\subsection{AdJUSTMENTS}

In order to obtain the aerodynamic forces applied only on the model, the drag of the endplates and the rod which hold the model in the model had to be obtained because it is also being measured by the drag scales, for this purpose the endplates attached with the rod where mounted and the drag force was measured by scales A and B.

Then, the drag force of the rod was computed by means of Eq. (4) using as its drag coefficient the one for a cylinder reviewed in [10] with the corresponding Reynolds number.

\section{RESUlts AND Discussion}

Figs. 7 - 10 show $C_{L}$ versus $A O A, C_{D}$ versus $A O A, C_{L}$ versus $C_{D}$ and $C_{M}$ versus $A O A$ of four wings which have a NACA 2415 airfoil as a base shape and a step on the suction side located according to Fig. 5. Each graph also presents obtained experimental results of the original NACA 2415 for further comparison. All the wings were tested at a Reynolds number of 100000 .

Concerning the lift coefficient, shown in Fig. 7, it can be seen that the location of the step does not have influence on the slope of the lift curve, however as the step moves towards the leading edge, the lift curve moves upwards, therefore this affects the values of the lift coefficient. The 2415-3 airfoil has the lowest lift for all angles of attack and its behavior is close to a symmetric airfoil (almost zero lift at zero angle of attack). The curve is linear until 14 degrees of AOA where an abrupt decrease begins which corresponds to the stall point.

The 2415-4 airfoil lift coefficient at zero angle of attack is approximately higher by 0,07 than the corresponding value for the 2415-3. The lift curve of the airfoil is not linear, at 6 degrees of AOA the curve follows the same path of the one for the 2415-3 airfoil curve until an AOA of 14

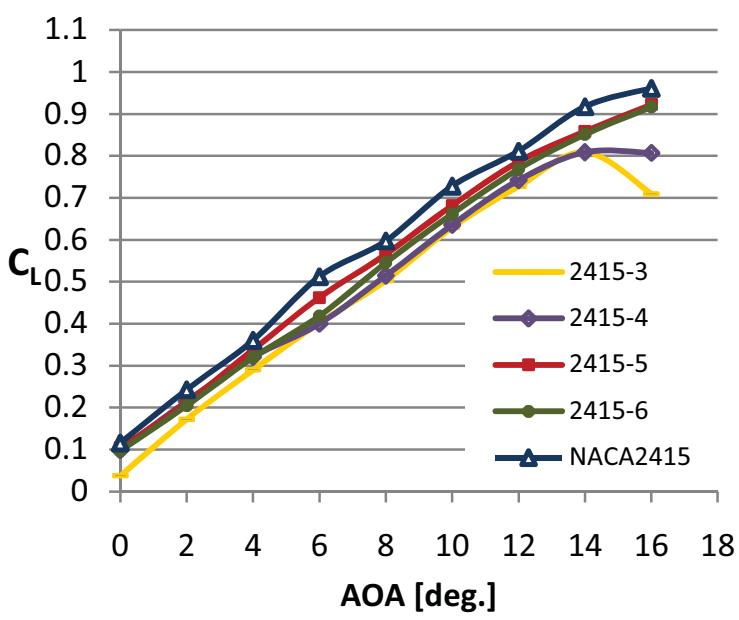

Fig. 7. Experimental lift coefficient graph for all airfoils models. degrees where a low decrease starts. The results show that the 2415-3 and 2415-4 ¿Luis Velazquez, Jiří Nožička, Jan Vavřín; luis.velazquez@fs.cvut.cz. Faculty of Mechanical Engineering, Czech Technical University in Prague, Techicka 4, 16606 Praha 6. 
airfoils have approximately the same stall point at 14 degrees of AOA but after this point, the decrease in lift for $2415-3$ airfoil is much more abrupt.

The lift coefficient behavior for 2415-5 and 2415-6 airfoils is very similar. The curves start at the same value of $C_{L}$, like 2415-4 airfoil but their path is approximately linear until 12 degrees of AOA where the slope begins to shrink moderately. The presence of the stall point for these curves is not shown very clear but it can be assumed that is very next to 16 degrees of AOA.

The original airfoil lift curve has slightly higher values of $C_{L}$ for all $A O A$ but its behavior is almost the same; the stall region begins after 15 degrees of AOA. These characteristics were expected since the step produces a sudden change in the pressure distribution along the upper side of the airfoils which contributes to decrease the lift.

In Fig. 8 above it is possible to see the drag coefficient versus the AOA for all the models tested. All of the modified airfoils reached approximately the same value of drag coefficient at zero angle of attack. The drag coefficient of the original airfoil value is about 0,01

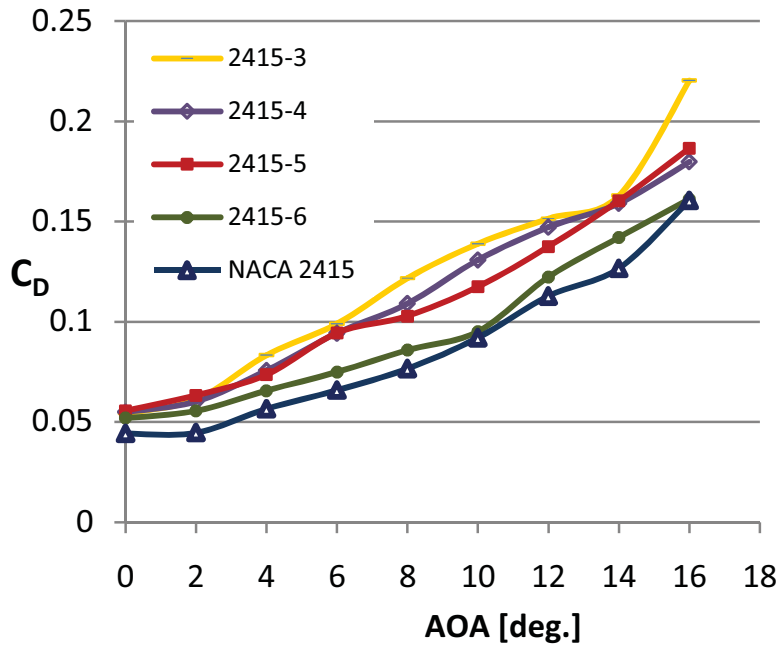

Fig. 8. Experimental drag coefficient graph for all airfoils models.

lower. A similar behavior of all drag curves is seen at 2 degrees of AOA.

The 2415-3, 2415-4 and 2415-5 airfoils presented similar drag characteristics for low $A O A$, specifically until 6 degrees, after this angle the values of $C_{D}$ are different until 14 degrees of AOA where the three curves present almost the same value of $C_{D}$. Also, between 6 and 14 degrees of AOA the 2415-3 airfoil presents high values of $C_{D}$ followed by the 2415-4 and 2415-5. After 14 degrees of AOA, the drag for 2415-4 and $2415-5$ is similar and the drag of 2415-3 airfoil showed a substantial increment.

The 2415-6 airfoil drag curve is similar to the original NACA 2415 airfoil curve; there is only certain shift at 10 degrees of AOA where both drag coefficient values are almost the same. From this AOA the drag of 2415-6 increases again until 16 degrees of AOA where the $C_{D}$ value of both airfoils equals. It is clear that the 2415-6 airfoil presented the best drag performance among all modified airfoils tested.

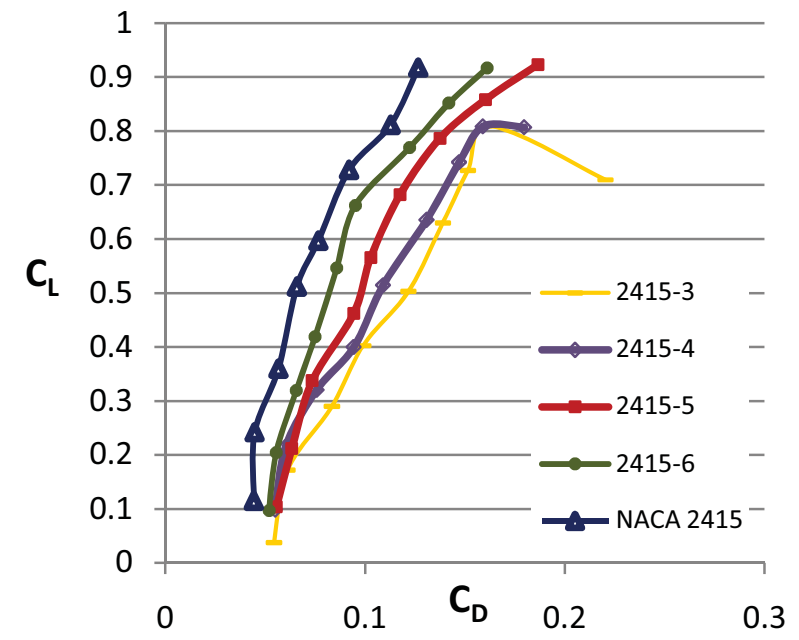

Fig. 9. Experimental polar graph for all airfoils models tested.

¿Luis Velazquez, Jiří Nožička, Jan Vavřín; luis.velazquez@fs.cvut.cz. Faculty of Mechanical Engineering, Czech Technical University in Prague, Techicka 4, 16606 Praha 6. 
The polar diagram shows a lot of information in a very compact format; therefore it is always considered the most important part of the results [8]. In Fig. 9 it is possible to see the polar curves of all airfoils tested.

One of the important points in this diagram is the optimum glide ratio (OGR) which is obtained drawing a line from the origin $\left(C_{L}=0, C_{D}=0\right)$ tangentially to each curve according to the diagram the results are:

- $\quad$ NACA 2415: OGR $=7,778$ at 9 degrees of $A O A$.

- 2415-6: OGR=6,947 at 10 degrees of AOA.

- 2415-5: OGR=6,0 at 10 degrees of $A O A$.

- 2415-4: OGR=5,161 at 13 degrees of AOA.

- 2415-3: OGR=5,142 at 13 degrees of AOA.

According to this the curves can be divided in two groups. In the first group (2415-3 and 2415-4 airfoils) the stall points were achieved at 14 degrees of AOA and the curves are convex between 4 and 14 degrees of AOA. In the second group (2415-5 and 2415-6 airfoils) the curves are convex in a very small range between 4 and 8 degrees of AOA and the stall point was not achieved at the measurable scale. The original airfoil polar is concave in almost the whole range of AOA. This diagram also can show a general idea of the aerodynamic performance of airfoils and it is possible to see that while the location of the step chordwise moves to the trailing edge, the aerodynamic performance of the airfoil tested increases.

The pitching moment coefficient was obtained by means of Eq. (6) and it is computed with respect to the leading edge according to the aerodynamic balance as shown in Fig. 10. In this chart it is possible to observe that the differences between the NACA 2415, 2415-6 and 2415-5 airfoils are minimal. The 2415-4 airfoil presents a lower moment until 4 degrees of AOA and after this point the moment values are similar to 2415-5, 2415-6 and NACA 2415 airfoils. The 2415-3 airfoil presented a lower pitching moment along all AOA.

In Fig. 11 it is possible to see the pitching moment coefficient with respect to a point located at $25 \%$ of the chord from the leading edge, this point is usually approximated as the aerodynamic center. This moment was computed by means of the following equation:

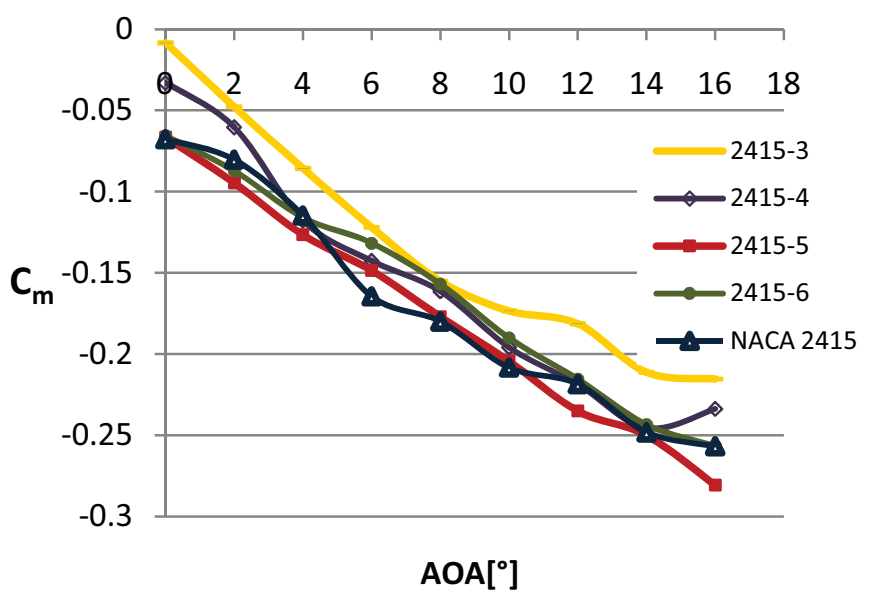

Fig. 10. Experimental pitching moment coefficient at the leading edge for all airfoils models tested.

$$
\left(C_{m}\right)_{1 / 4}=C_{m}+\frac{1}{4} C_{L}
$$

'Luis Velazquez, Jiří Nožička, Jan Vavřín; luis.velazquez@fs.cvut.cz. Faculty of Mechanical Engineering, Czech Technical University in Prague, Techicka 4, 16606 Praha 6. 
In theory, the aerodynamic center is the point at which the pitching moment coefficient for the airfoil does not vary with the angle of attack [8]. It can be seen also in Fig. 11 that the pitching moment coefficient for all models tested had very small differences with respect to the AOA, it was negative which indicates a pitch down tendency and the values were in a range between 0,00 and $-0,04$.

In Fig. 12 it is possible to observe the lift to drag ratio $C_{L} / C_{D}$ versus $A O A$, this diagram is used to see the performance of all airfoils tested and along all $A O A$, in this manner it is clear that all modified profiles reached their maximum $C_{\downarrow} / C_{D}$ in a smaller range of angle of attack comparing to the NACA 2415 airfoil, this one presents a maximum $C_{L} / C_{D}$ of 8 for a range between 6 and 10 degrees of AOA.

The maximum $C_{L} / C_{D}$ for $2415-6$ and 2415-5 airfoils is 7 and 6 respectively at 10 degrees of AOA. The 2415-4 and 2415-3 airfoils presented a maximum $C_{b} / C_{D}$ of approximately 5 in a range between 10 and 14 degrees of AOA.

The following section is devoted to different comparisons between obtained experimental and numerical results. Numerical results reviewed were obtained for every model for AOA between 0 and 16 degrees with a smallest increment of 4 degrees.

Concerning the lift coefficient,

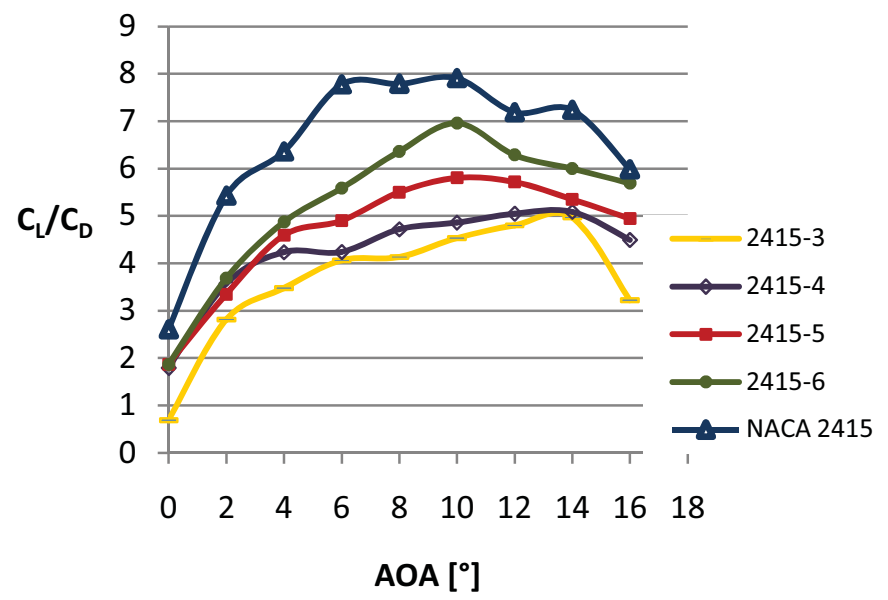

Fig.12. $C_{L} / C_{D}$ versus $A O A$ for all airfoil models tested.

experimental and numerical results are in good agreement; it is possible to see in Fig. 13 , where only two airfoils have been included on purpose for a better appreciation, that the differences are very small, for the case of the 2415-3 airfoil, the stall point could be seen clearer in the experimental results because this method had a smaller increment of the angle of attack. The behavior of the other airfoils is pretty similar and for that reason the curves were omitted.

¿Luis Velazquez, Jiří Nožička, Jan Vavřín; luis.velazquez@fs.cvut.cz. Faculty of Mechanical Engineering, Czech Technical University in Prague, Techicka 4, 16606 Praha 6. 
Concerning the drag coefficient, experimental and numerical results are similar, however some discrepancies are present. In Fig. 14 are shown the most representative cases of this discrepancies, only two airfoils have been included on purpose for a better appreciation. It is possible to see that in general, the numerical values for drag coefficients resulted slightly higher than the experimental ones. Since the method of computing forces used by the software consists in summing the dot product of the pressure

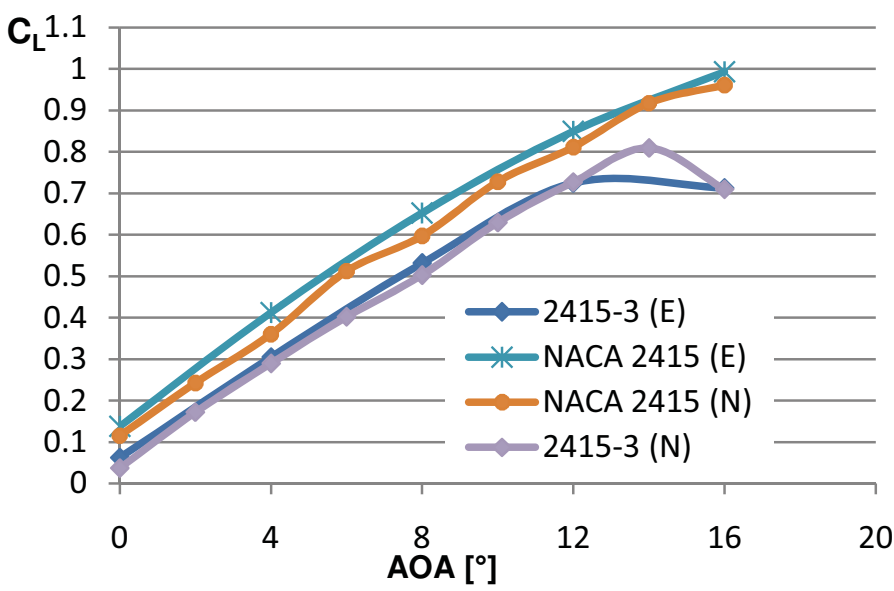

Fig. 13. Numerical and experimental lift coefficient for two airfoils tested.

and viscous forces on each face with the specified force vector, in this case the force is parallel to the flow direction, only abscissas, therefore, the theory of the software which predicts the force and then the coefficient does not seem very accurate.

Concerning the pitching moment coefficient it is possible to observe in Fig. 15 that experimental and numerical results present significant differences, for instance in these two cases experimental results are higher than numerical ones and so on for the rest of the models tested.

Since the theory of the software which predicts the pitching moment and then its coefficient consists in summing the cross products of the pressure and viscous force vectors for each face with the moment vector, which is the vector from the specified moment center to the force origin. Based on this it can be said that these differences can be due to possible inaccuracy in the measurements with the wire balance. For precise determination of these coefficients it would necessary to perform these measurements with another type of balance and compare the results.

To finish, in Fig. 16 it is possible to see an interesting chart which shows the ratio of $C_{L} / C_{D}$ of every modified airfoil and $C_{L} / C_{D}$ of the original NACA 2415 airfoil for every AOA.

'Luis Velazquez, Jiří Nožička, Jan Vavřín; luis.velazquez@fs.cvut.cz. Faculty of Mechanical Engineering, Czech Technical University in Prague, Techicka 4, 16606 Praha 6. 
This graph represents a measure of the performance of every airfoil compared to the original NACA 2415 airfoil's performance. It is possible to say that the performance of all modified airfoils is significantly lower than the original until 10 degrees of AOA, after this, the 2415-6 airfoil's performance is approximately $90 \%$ of the performance of the original NACA 2415 airfoil. The performances of the other

modified airfoils are lower than $80 \%$ of the original one. The situation where separation of

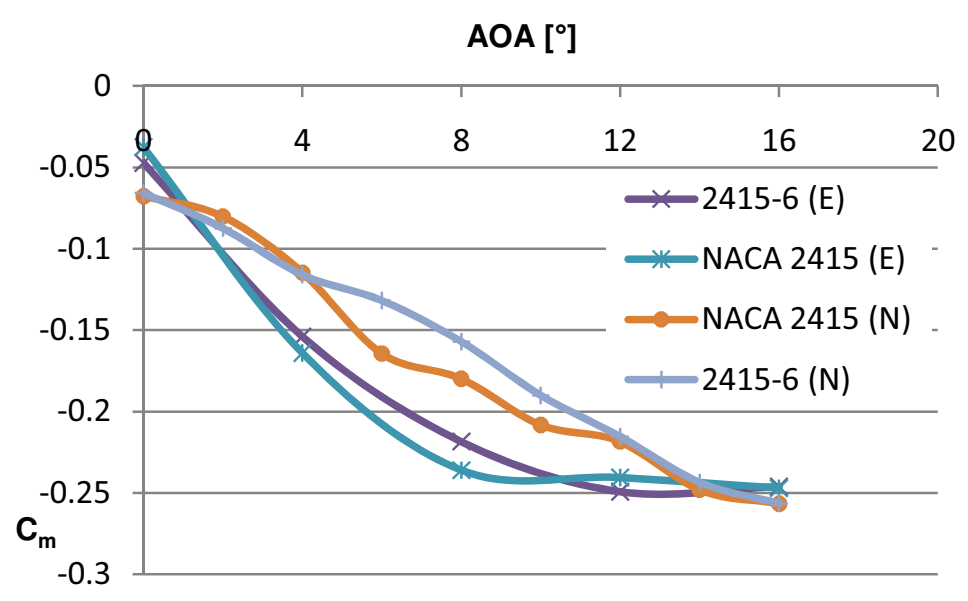

Fig. 15. Numerical and experimental pitching moment coefficient for two airfoils tested.

flow occurs on the step can be seen at angles which are lower than 8 degrees and all of modified airfoils have a significantly low performance than the original. According to all previously mentioned the 2415-6 airfoil meets the best conditions for gliding flight, since its aerodynamic performance was the closest to the original base airfoil among the other models, therefore it should be selected for further investigation including blowing through the propulsion outlet (step).

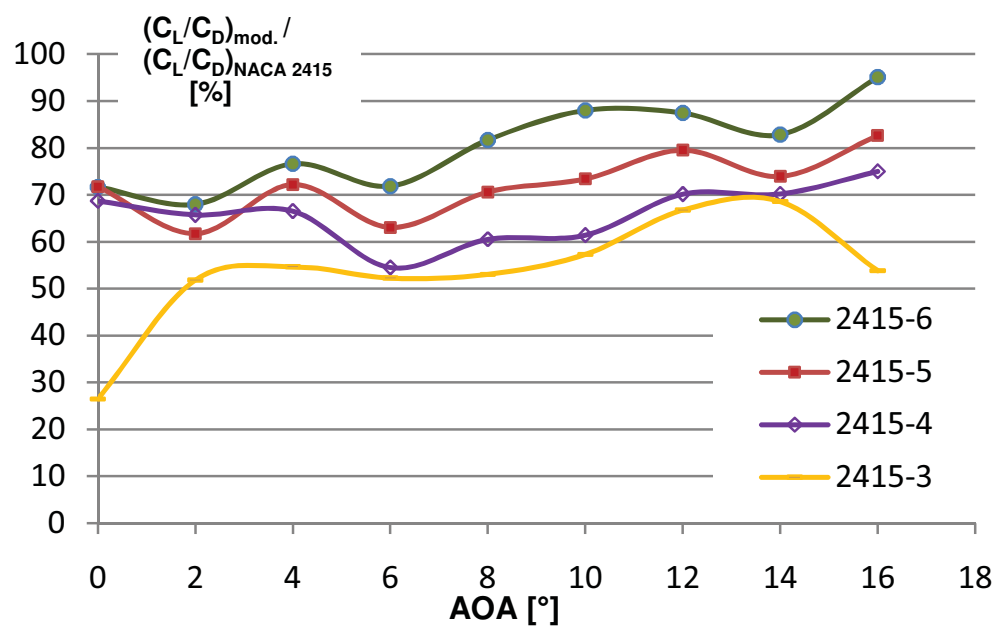

Fig. 16. Ratio of $C_{L} / C_{D}$ of every modified airfoil and $C_{L} / C_{D}$ of the original NACA 2415 airfoil.

\section{CONCLUSION}

The main objective of this work was to perform wind tunnel tests of a base airfoil and some modifications of this one. Four modified airfoils were built and tested. The influence of the location of the blowing outlet has been analyzed based on the results which showed that the aerodynamic performance of the airfoil increases when the step moves towards the leading edge. Results have been compared to numerical ones from references and found in good agreement. Finally the selection of the airfoil with the best 'Luis Velazquez, Jiří Nožička, Jan Vavř́n; luis.velazquez@fs.cvut.cz. Faculty of Mechanical Engineering, Czech Technical University in Prague, Techicka 4, 16606 Praha 6. 
aerodynamic performance is held and laid on the 2415-6 airfoil. However, it is recommended to design a system which allows performing tests of all these airfoils with blowing and make comparisons with results obtained in this paper in order to select the definitive airfoil for the unmanned aerial vehicle.

\section{REFERENCES}

[1] Selig M.S., Lyon C.A., Giguere P., Ninham C., Guglielmo J.J.(1996): "Summary of Low-Speed Airfoil Data", Vol. 2, Viginia Beach, SoarTech Publications.

[2] Barlow J.B., Rae W. H., Pope A.(1999): "Low-Speed Wind Tunnel Testing", $3^{\text {rd }}$ ed., New York, John Wiley \& Sons, Inc.

[3] Velazquez L., Nožička J.(2009): Design of Precision Aerodynamic Balance for Unmanned Aerial Vehicles, Proceedings of Experimental Fluid Mechanics 2009. Liberec.

[4] Abbott I.H., Von Doenhoff A.E.(1959): "Theory of Wing Sections", New York, Dover Publications Inc.

[5] Velazquez L. (2010): "Development of an airfoil for an unmanned aerial vehicle with internal blowing propulsion system". PhD Thesis. CTU in Prague.

[6] Velazquez L., Nožička J.(2009): "Low Speed Wind-Tunnel Testing for an Unmanned Aerial Vehicle", Proceedings of Colloquium of Fluid Dynamics 2009, Prague, 2009.

[7] Tropea, Yarin, Foss (Eds.)(2007): "Springer Handbook of Experimental Fluid Mechanics", Springer.

[8] Clancy L.J.(1986): "Aerodynamics", Sterling Book House, Mumbai.

[9] http://profily.fs.cvut.cz/, Laboratory of Department of Fluid Dynamics and Power Engineering of the CTU. Section Airfoils and Straight Blade Cascades.

[10] Vogel S.(1996): Life in Moving Fluids: The Physical Biology of Flow, Princeton University Press, Princeton.

¿Luis Velazquez, Jiří Nožička, Jan Vavřín; luis.velazquez@fs.cvut.cz. Faculty of Mechanical Engineering, Czech Technical University in Prague, Techicka 4, 16606 Praha 6. 